\title{
Calendula officinalis L. (ASTERACEAE): ASPECTOS BOTÂNICOS, ECOLÓGICOS E USOS
}

\section{Calendula officinalis L. (ASTERACEAE): BOTANICAL AND ECOLOGICAL ASPECTS AND USES}

\section{CITADINI-ZANETTE', Vanilde'; NEGRELLE, Raquel R. B.'; BORBA, Elder Tschoseck $^{3}$}

\begin{abstract}
1'Doutora em Ecologia e Recursos Naturais, Programa de Pós-Graduação em Ciências Ambientais (PPGCA) - UNESC, vcz@unesc.net

${ }^{2}$ Doutora em Ecologia e Recursos Naturais, Laboratório OIKOS - UFPR, negrelle@ufpr.br

${ }^{3}$ Mestre em Ciências Ambientais, PPGCA-UNESC, elder.tb@gmail.com
\end{abstract}

\section{Resumo:}

Calendula officinalis L. (Asteraceae) tem sido amplamente utilizada por suas propriedades antiinflamatórias, anti-espasmódicas, emenagogas, colagogas, sedativas, sudoríficas, vulnerárias e bactericidas. Dada sua importância terapêutica, apresenta-se resultado de pesquisa exploratório-descritiva incluindo características botânicas, agronômicas, ecológicas e de uso dessa espécie, visando subsidiar o incremento de seu cultivo no Brasil.

Palavras-chave: Calêndula; planta medicinal.

\section{Abstract:}

Calendula officinalis L. (Asteraceae) has been widely used by its anti-inflammatory, anti-spasmodic, emenagoge, colagoge, sedative, sudoriferous, wound-healing and bactericidal properties. Given to its therapeutic importance, the results from an exploratory-descriptive research including species usage, botanical, agronomical, and ecological characteristics are presented, aiming to subsidize the growth of the species cultivation in Brazil.

Key-words: Marigold, medicinal plant.

\section{CLASSIFICAÇÃO BOTÂNICA}

Inserido em Asteraceae, o gênero Calendula tem seu nome derivado da palavra latina - Calendae - que significa "primeiro dia de cada mês", de onde se derivou também a palavra calendário, baseado no ciclo solar. Este gênero inclui 29 espécies (MOBOT, 2010), dentre estas Calendula officinalis L., planta herbácea amplamente 
cultivada em várias partes do mundo para fins ornamentais, cosméticos e medicinais (RAMOS et al., 1998). No Brasil, a espécie é popularmente conhecida como calêndula, calêndula-hortense, maravilha, maravilha-dos-jardins, malmequer, malmequer-dojardim, flor-de-todos-os-males, margarida-dourada e verrucária (SILVA et al, 2005; S I L V A J U N I OR , 2006 ; L OR E N Z I; M A T O S , 2008 ).

Em espanhol é denominada caléndula, maravilla, copetuda, capetuda, flor de muerto, mercadela e flamenquilla (GIL et al., 2000). Em inglês, é designada como marigold (nome originado na Idade Média devido a uma lenda que associava a virgem Maria com as flores douradas da calêndula) assim como holligold, goldbloom e marybud (ROIG, 1974; MUÑOZ, 1987).

Em outros países é conhecida como ringelblume, todtenblume (Alemanha), souci, souci des jardins (França), chin chan ts'ao (China), calendola, calendula, callandria, calenzola (Itália), belas noites, maravilha, bem me queres, calêndula hortense (Portugal), galbinele (Romênia) e ringblomma (Suécia) (CENTENO, 2004; MULEY et al., 2009).

Segundo APG III (2009) a calêndula está taxonomicamente categorizada como:

\section{Clado EUASTERÍDEAS II \\ Ordem ASTERALES}

Família ASTERACEAE Bercht. \& J. Presl, 1820 (Compositae, nom.cons.)

Subfamília ASTEROIDEAE

Tribo CALENDULEAE

Gênero Calendula L., 1753

Espécie Calendula officinalis L. in Sp. PI. 2: 921, 1753

\section{ORIGEM E DISTRIBUIÇÃO}

Várias origens são mencionadas para a calêndula, como Egito (LUZ et al., 2001), Europa central, leste e sul (WHO, 2002), Ilhas Canárias e Região Mediterrânea (SILVA JUNIOR, 2006; LORENZI; MATOS, 2008). Atualmente, é considerada planta cosmopolita cultivada em várias partes do mundo, incluindo o Brasil (BERTONI et al., 2006).

\section{DESCRIÇÃO BOTÂNICA}

C. officinalis é uma planta herbácea anual, que varia de 30 a $60 \mathrm{~cm}$ de altura, com raízes fasciculadas, ligeiramente amareladas e cilíndricas; apresenta caule anguloso, curto e sólido, ereto ou prostrado, pubescente; as folhas são ligeiramente denteadas, alternas, lanceoladas, com pelos glandulares em ambas as faces; as inferiores são espatuladas, 
obtusas ou agudas no ápice, com 10-20 cm de comprimento e 1-4 cm de largura; as superiores são oblongas a lanceoladas e mucronadas no ápice, com 4-7 cm de comprimento; brácteas involucrais com $7-15 \mathrm{~cm}$ de comprimento, revestidas de longos pelos glandulares; inflorescências capítulos no ápice dos caules, de 3-7 cm de diâmetro, com flores de cores heterogêneas, podendo variar do amarelo ao alaranjado; as flores centrais são tubuladas e estéreis, já as periféricas são liguladas e férteis; apresentam frutos secos tipo aquênio, estreitamente oblongos e curvos (WHO, 2000; PDR, 2000; LORENZI; MATOS 2008) (Figura 1).

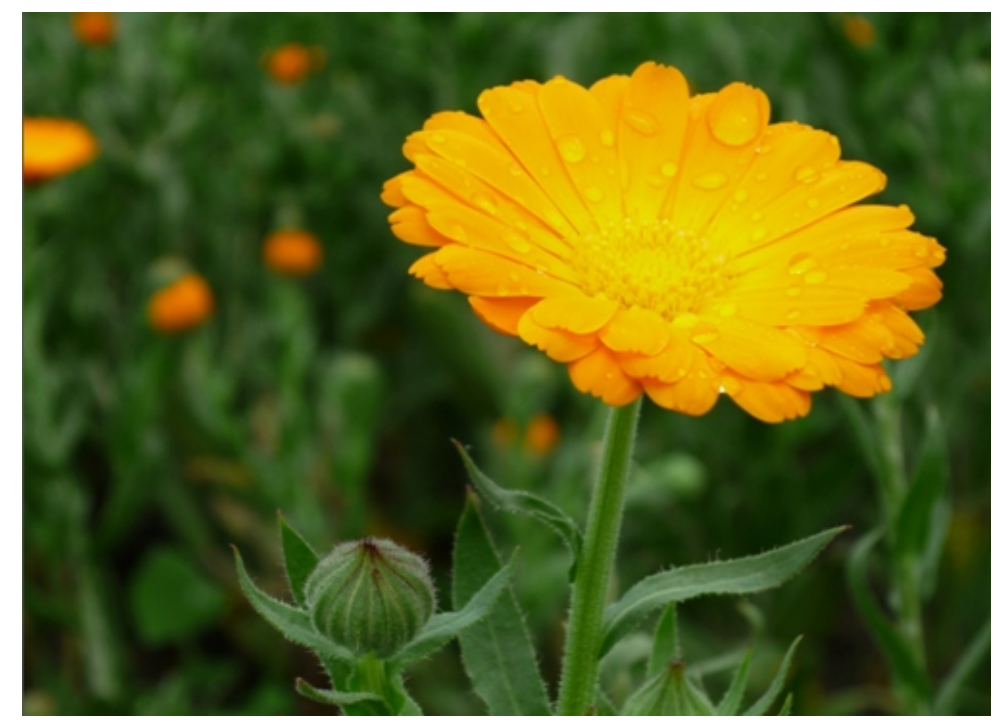

FIGURA 1 - Calendula officinalis L.: detalhe da inflorescência. (Foto: Elder T. Borba out. 2008)

\subsection{Descrição detalhada da inflorescência}

Por ser uma planta cultivada desde a antiguidade, existem numerosas variedades, que se diferenciam fundamentalmente pelo tamanho, cor e complexidade da corola (LUZ et al., 2001).

Capítulos solitários, geralmente com 3-7 cm de diâmetro; brácteas involucrais lineares e acuminadas, com margem estreito-escariosa, revestidas de pelos glandulares, dispostas em 1-2 verticilos, com 7-15 mm de comprimento; receptáculo floral plano e sem brácteas interflorais; flores liguladas amarelas ou alaranjadas e as tubuladas concolores com as liguladas, estas medem 2-3 cm de comprimento e 5-7 mm de largura, tridentadas no ápice e dotadas de abundantes tricomas tectores pluricelulares e bisseriados na base; flores tubuladas com corola pentalobada, mais curtas $(5 \mathrm{~mm})$ que as liguladas e com menos tricomas tectores na base (WHO, 2002; CENTENO, 2004). 


\subsection{Elementos anátomo-microscópicos característicos}

Apresenta flores liguladas revestidas na base por abundantes tricomas tectores pluricelulares bisseriados e alguns tricomas glandulares pedicelados bisseriados de comprimento variável; flores tubuladas, com os mesmos tipos de tricomas na base, além de outros tricomas tectores pluricelulares unisseriados e alguns glandulares com pé curto e cabeça secretora, formada por vários estratos de células superpostas (CENTENO, 2004).

Células epidérmicas internas das flores liguladas alongadas, retangular, com parede lisa e cutícula fracamente estriada; estômato ausente; células externas da epiderme semelhantes às internas, mas com 3 ou 4 estômato anomocítico; tricomas numerosos no tubo, bisseriado; células epidérmicas do estigma com parede lisa, poligonal; flores tubuladas ou do disco, com células da epiderme externa alongadas, com parede lisa ou ligeiramente sinuosa, estômato ausente; tricomas abundantes abaixo do ponto de inserção dos estames, principalmente glandular, unisseriado ou bisseriado; dentro da porção superior da antera há uma camada de células isodiamétricas a alongadas, com parede moderadamente espessa, lignificada e escavada; grãos-de-pólen esféricos, até 45 um de diâmetro, com tricolporados, exina finamente granular, com numerosos espinhos curtos; ápice do estigma coberto por papilas bulbosas curtas (BRUNETON, 2001; WHO, 2002).

\subsection{Características organolépticas}

Odor característico, de fraco a forte, com sabor amargo e aromático (PDR, 2000, WHO, 2002, CENTENO, 2004).

\section{EXIGÊNCIAS AMBIENTAIS}

A calêndula é considerada uma espécie rústica por ser pouco exigente ao tipo de solo, ainda que prefira solos argilosos (LUZ et al., 2001; CENTENO, 2004), férteis, bem drenados, ricos em matéria orgânica e permeáveis (CASTRO; CHEMALE, 1995; SILVA JUNIOR, 2006).

É uma planta heliófila que necessita de no mínimo quatro horas diárias de sol. Prefere climas temperados, mas resiste às geadas e às estiagens; cresce em altitude que vão desde o nível do mar até $1000 \mathrm{~m}$. A temperatura ótima para a germinação está entre 18 e $24^{\circ} \mathrm{C}$, porém nas fases seguintes suporta temperaturas superiores (LUZ et al., 2001). Em temperaturas noturnas muito elevadas, as flores são menores (SILVA JUNIOR, 2006; OSAIDA et al., 2009). Os climas secos e amenos são mais favoráveis ao se u cultivo. (CASTRO; CHEMALE, 1995). 


\section{FENOLOGIA}

A calêndula floresce quase todo o ano, exceto em períodos de estiagem (CORREA JUNIOR et al., 1994). A floração mais intensa ocorre no final da primavera até no final do verão (FRANCO, 2005; OSAIDA et al., 2009). As flores abrem ao nascer do sol e fecham ao entardecer e, dependendo do ambiente, suas estruturas florais podem ter variações de cor e tamanho (VAZ; JORGE, 2006; SILVA JUNIOR, 2006; OSAIDA et al., 2009).

A semeadura ocorre no final do outono (LUZ et al., 2001) ou final do inverno (SILVA JUNIOR, 2006), desenvolvendo um ciclo de aproximadamente 4-5 meses.

\section{CULTIVO}

A calêndula é uma planta anual que se adapta bem aos solos férteis, úmidos e permeáveis, bem drenados, ricos em matéria orgânica, profundos e permeáveis (FUENTES et al., 1986). A melhor forma de propagação é semeadura direta no campo em linha (Montanari Júnior, 2000) e em canteiros, que é recomendado para espécies de ciclo curto e porte pequeno como a calêndula (CORREA JR. et al., 1994). As covas devem estar com 0,40 m de espaçamento entre linhas e de 0,30 m na linha, sendo plantadas três sementes/ cova com profundidade de $2 \mathrm{~cm}$ (MONTANARI JR, 2000).

O tipo de diásporo (alado, navicular e orbicular alado) pode influenciar o crescimento em altura e área foliar das plantas (BERTOLINI et al., 2001). Conforme Vieira et al. (2006), as cores dos capítulos florais das plantas matrizes nem os tipos de diásporos influenciam a produção de matéria frescas e seca de capítulos florais. Entretanto, estes fatores podem influenciar o número de capítulos produzidos, sendo a maior produção média obtida com diásporos alados e capítulos laranja.

A semeadura deve ser realizada nos meses de julho a agosto. $O$ espaçamento indicado é de $20 \times 30 \mathrm{~cm}$ entre plantas (EMBRAPA, 2006).

A adubação equilibrada é fundamental para a obtenção de plantas medicinais mais produtivas, resistentes a pragas e doenças e com maiores teores de fármacos (MARTINS et al., 1994). No caso da calêndula, a adubação nitrogenada é importante para incrementar o desenvolvimento da planta, sendo a sua deficiência caracterizada por redução no crescimento e no tamanho das folhas, diminuindo, portanto, a produção de massas frescas e secas (MATTOS, 1996).

A adição ao solo de nitrogênio e de fósforo, na forma de uréia e de superfosfato triplo, possibilita obtenção das plantas mais altas (MOREIRA et al., 2005). Vieira et al. (1999) observaram que a altura média final das plantas de calêndula variou de 29,9 a $39,9 \mathrm{~cm}$, quando cultivadas, respectivamente, com 0 t ha- 1 de cama-de-frango +50 $\mathrm{kg} \cdot \mathrm{ha}^{-1}$ de $\mathrm{P}_{2} \mathrm{O}_{5}$ na forma de superfosfato simples e 7 t.ha $^{-1}$ de cama-de-frango +100 
kg.ha' ${ }^{-1}$ de $\mathrm{P}_{2} \mathrm{O}_{5}$.

Segundo Barboza et al (2009), para se obter maior produção de massa seca de capítulos florais, componente de maior importância comercial, a calêndula deve ser cultivada utilizando adubação com HH $40 \mathrm{~kg} \cdot \mathrm{ha}^{-1}$ de $\mathrm{P}_{2} \mathrm{O}_{5}$ e H" $8.000 \mathrm{~kg}$.ha-1 de cama-defrango.

Em relação a reguladores de crescimento, a aplicação de $15 \mathrm{mg}$ de paclobutrazol por planta incrementou significativamente a produção de ramos secundários por planta (32,22\%), reduzindo a altura destas plantas. Contudo, o índice $(6,99)$ de área foliar máximo, fresco $(80,06 \mathrm{~g})$ e biomassa foliar seca $(9,66 \mathrm{~g})$ foi registrado com paclobutrazol $10 \mathrm{mg} /$ planta. Esta quantidade também aumentou significativamente o peso de sementes/flor $(0,31 \mathrm{~g})$, peso de 100 sementes $(1,08 \mathrm{~g})$, peso/planta de semente (7,26 g) e produção/m² (145,2 g) (SINGH, 2004).

A calêndula é uma planta sensível à falta de água nos períodos de estiagem, 0 que acarreta um comprometimento de sua produtividade demandando sistemas de irrigação nas áreas de plantios onde esta situação esteja prevista (SILVA JR., 1997; GAZIM, 2007).

\section{COLHEITA E SECAGEM}

A colheita deve ser feita quando as sumidades floridas estão em plena floração, quando os capítulos vão sendo cortados escalonadamente à medida que se abrem (CENTENO, 2004).

Independente da época de plantio, os melhores resultados são obtidos com secagem a sol (4-6 dias, temp. média $=33^{\circ} \mathrm{C}$, umidade relativa $\left.=52 \%\right)$ e a $40{ }^{\circ} \mathrm{C}(2-3$ dias), dado que tempos mais prolongados de secagem favorecem a hidrólise enzimática dos compostos fenólicos (GARCIAet al., 1996).

\section{CONSTITUINTES QUÍMICOS}

Estudos fitoquímicos realizados com as flores e os receptáculos de calêndula registram um amplo espectro de compostos químicos (VALDÉZ; GARCÍA, 1999), sobretudo flavonóides (PIETTA et al., 1992, 1994), carotenóides (SERGEEVA, 1977, STEVENSON, 1961; ALONSO, 1998), polissacarídeos (WAGNER, 1984), saponinas triterpênicas (PARKHURSI, 1975, ALONSO, 1998), triterpenos (TOMAS, 1978, WILKOMIRSKI, 1985), ácidos fenólicos (SWISTEK, 1978), cumarinas (DERKACH,1986; PDR, 2000), taninos (OCIOSZYNSKAYA, 1977) além de ésteres de ácidos graxos, hidrocarbonetos e ácidos graxos (HAMBURGER et al., 2003), poliacetilenos, esteróis, sesquiterpenos glicosídeo (PDR, 2000) e um óleo volátil $(0,1$ - 
$0,2 \%$ ) muito abundante em sesquiterpenos hidrocarbonetos e alcoóis (CHALCHAT et al., 1991; PDR, 2000; RADULESCU et al., 2000; CRABAS et al., 2003).

As substancias químicas majoritárias identificadas por cromatografia gasosa acoplada à espectrometria de massas (CG/MS), foram sesquiterpenos hidrocarbonetos e álcoois; d-cadineno (12 - $23 \%$ ) e a-cadinol (20 a 25\%) (GAZIM et al., 2007) (Tab.1)

TABELA 1. Substâncias químicas identificadas na fração volátil de Calendula officinalis. Fonte: GAZIM et al. (2007).

\begin{tabular}{llccc}
\hline$N^{\text {o. }}$ & Substância & Area $\%$ & IRR calc. & IRR lit. \\
\hline 1 & $\alpha$-copaeno & 0,96 & 1365 & 1376 \\
2 & $\alpha$-ionona & 1,54 & 1421 & 1426 \\
3 & $\alpha$-humuleno & 1,18 & 1444 & 1454 \\
4 & Geranilacetona & 1,61 & 1452 & 1453 \\
5 & $\gamma$-muuroleno & 2,27 & 1472 & 1477 \\
6 & $\beta$-ionona & 3,25 & 1484 & 1485 \\
7 & Ledeno & 2,30 & 1488 & 1493 \\
8 & $\alpha$-muuroleno & 5,62 & 1497 & 1499 \\
9 & $\gamma$-cadineno & 8,93 & 1511 & 1513 \\
10 & $\delta$-cadineno & 22,53 & 1522 & 1524 \\
11 & $\alpha$-cadineno & 0,92 & 1533 & 1538 \\
12 & $\alpha$-calacoreno & 2,32 & 1539 & 1542 \\
13 & Oxido de cariofileno & 0,52 & 1547 & 1581 \\
14 & Copaen-4- -ol & 0,64 & 1566 & 1584 \\
15 & b-oplopenona & 1,73 & 1568 & 1606 \\
16 & Viridiflorol & 2,25 & 1585 & 1590 \\
17 & Ledol & 1,30 & 1595 & 1565 \\
18 & 1,10 -di-epi-Cubenol & 0,87 & 1608 & 1614 \\
19 & 1-epi-cubenol & 1,60 & 1621 & 1627 \\
20 & epi $\alpha$-muurolol & 12,87 & 1639 & 1641 \\
21 & $\alpha$-cadinol & 20,40 & 1654 & \\
22 & Cadaleno & 0,76 & 1671 & \\
\hline
\end{tabular}

IRR calc- Índice de retenção relativo calculado em coluna capilar DB5 (5\% fenilmetilsiloxane). IRR lit.- Índice de retenção relativo encontrado na literatura em coluna capilar DB5. EM- Comparação com Espectros de Massas da espectroteca Wiley 275. Lit.- Comparação dos Índices de Retenção e/ou dos Espectros de Massas com a Literatura (ADAMS, 1995).

C. officinalis cultivada na região Noroeste do Paraná, onde foi aclimatada, apresentou semelhanças com a mesma produzida na região mediterrânea no que diz respeito à composição química da fração volátil quando comparada com dados da literatura obtido pela técnica de arraste a vapor. Concluiu-se que oferecendo à planta condições ideais de plantio, de coleta, de secagem e de extração, seria possível obter fração volátil com constituintes químicos semelhantes àqueles obtidos em seu habitat natural (GAZIM et al., 2007). 


\section{USOS EAPLICAÇÕES}

Dada a beleza de suas inflorescências amarelo-alaranjadas e seu amplo período de floração, $C$. officinalis tem sido cultivada em quase todo o mundo como planta ornamental tanto para vasos como para jardins (CROMACKE; SMITH, 1996). Estas plantas e suas inflorescências podem ser utilizadas como inseticida natural (MARTINS et al., 1994).

Os capítulos são utilizados, tanto popularmente quanto pela indústria alimentícia, para condimentar sopas, ensopados, omeletes, queijos, carne assada e guisados, bem como para colorir manteiga, pudins e licores como sucedâneo do açafrão. As folhas e os caules também são utilizados como temperos (LUZ et al., 2001; SILVA JUNIOR, 2006; OSAIDA et. al. 2009).

Inúmeros outros usos medicinais e farmacêuticos são vinculados à calêndula, conjugados ao uso interno e externo, em diferentes formas de preparo que incluem desde o seu consumo in natura em saladas assim como infusão, decocção, tinturas, extratos, pomadas, cataplasmas, ungüentos, banhos entre outras (PLANTAMED, 2010). Embora sejam citados o uso do caule e das folhas secas (SILVA JR, 2006), das sementes (FRISTCHE et al., 199) e de toda a planta (PDR, 2000), a flor é a parte mais utilizada e estudada (HAMBURGER et al., 2003; GAZIM et al., 2007).

A calêndula é utilizada no campo da cosmética e farmácias de manipulação em cremes hidratantes (produtos solares pré e pós- exposição) já que suas saponinas, as gomas e as mucilagens têm grande capacidade umectante (NARDI et al., 1991), além de fazer parte na composição de preparações de medicamentos para eritemas solares, queimaduras e dermatoses secas (SIMÕES et al., 2003; ALONSO, 2008). O óleo calêndico, o principal componente das sementes de calêndula, contém um isômero do triacilglicerol, precursor do ácido -linoleico, é também de interesse das indústrias cosméticas (FRITSCHE et al., 1999)

Formas galênicas preparadas a partir dos extratos das flores de $C$. officinalis são amplamente utilizadas como antiinflamatórias e cicatrizantes em doses que variam entre 1,0 a 2,0 g de flor seca por $150 \mathrm{~mL}$ de água ou 8,8 a 17,6 $\mathrm{mg}$ de flavonóides (SCHEFFER, 1979; BLUMENTHAL, 1998).

Os triterpenos, sobretudo os monoésteres de faradiol, têm sido relatados como os principais responsáveis pela atividade antiinflamatória da planta (DELLA LOGGIA et al., 1994; AKIHISA et al., 1996). O triterpeno alcoólico taraxast- 2- em- -ol isolado de calêndula apresentou potente efeito antiinflamatório em camundongos, quando comparado a drogas comerciais como hidrocortisona e indometacina (AKIHISA et al., 1996). Os ésteres farodiol e - taraxasterol obtidos a partir de flores de calêndula apresentaram efeito anti-edematoso superior à indometacina quando da indução de edema na orelha de ratos (ZITTERL-EGLSCER et al., 1997). 
A ação cicatrizante igualmente tem sido cientificamente comprovada. De acordo Pagnano et al. (2008), a tintura de calêndula a 5\% propiciou obtenção dos maiores valores médios das células envolvidas no processo cicatricial, os fibroblastos, resultando em resposta mais satisfatória na cicatrização que os outros tratamentos aplicados sobre feridas cutâneas experimentais em coelhos. Similarmente, Duran et al. (2005) reportam que o uso da calêndula no tratamento de pacientes que apresentavam úlceras venosas promoveu aceleração na cicatrização das mesmas. Conforme latsyno et al. (1978), o ácido oleonólico e calendulozida - B triosida isolados de rizomas de calêndula apresentaram ação antiulcerativa em três tipos de úlceras de diferentes origens bem como certa ação antiflogística e sedativa.

Alguns constituintes químicos de calêndula também são associados à atividade antitumoral (ELIAS et al., 1990). Conforme Akihisa et al. (1996), o helianol, triterpeno isolado das flores desta espécie pode ser considerado um potente agente antitumoral. Outros três polissacarídeos isolados das flores através do fracionamento em etanol e filtração em gel também apresentariam esta propriedade (VARLJEN, 1989).

De acordo a Jimenez-Medina et al. (2006), o extrato de calêndula ativado por raio laser (LACE) inibiu o crescimento in vitro de várias linhas de células tumorais, apresentando também atividade antitumoral in vivo em ratos nus. A molécula $\mathrm{PF}_{2}$, isolada desta mesma planta tem sido indicada como provável estimulante dos linfócitos humanos, auxiliando no tratamento de câncer (JIMENEZ-MEDINA et al., 2004).

Observou-se que o extrato de $C$. officinalis induziu a formação de vasos sanguíneos, resultado importante no processo de granulação (PDR, 2000; Schulz et al., 2002).

Outras atividades farmacológicas que têm sido associadas à calêndula são: imunomodulatória (Amirghofran et al., 2000, ALONSO 1998, PARENTE et al., 2004) por estimulação na granulocitose; antimutagênica e antiviral (Kalvatchev et al, 1997; PDR, 2000); antimicrobiana (DUMENIL et al., 1980; GRACZA, 1987; HSIEH et al. 2001) e antimicótico contra fungos dermatofitos (GIL et al., 2000). Outras atividades biológicas tais como moluscicida (HELALY et al., 1999); o óleo essencial como nematicida (PEREZ et al., 2003); genotóxica (RAMOS et al., 1998); larvicida (EL-SHAZLY; HUSSEIN, 2004); e antiplasmódica (BOYOM et al., 2003).

Adicionalmente, seu óleo essencial é usado para preparar perfumes de aroma silvestre, mesmo que seu odor não seja muito agradável (RIVERA et al., 1995 apud CENTENO, 2004). O aroma característico das flores de calêndula é associado à presença dos sesquiterpenos na fração volátil, dentre esses o d-cadineno que confere as notas verdes, doces e refrescantes; e o a-cadinol responsável pelas notas amadeiradas (REZNICEK; ZITTERL-EGLSEER, 2003).

C. officinalis também tem uso homeopático, sendo usada para ulceração 
produzida pelo frio, queimaduras da pele e cicatrização de feridas. No entanto a eficácia de seu uso não tem sido comprovada (PDR, 2000). Aleixo (2002 apud PARENTE, 2002) descreve várias formulações homeopáticas à base de $C$. officinalis e suas respectivas aplicações e Machado (2000) indica o uso homeopático da calêndula para a cura de uma série de afecções. O uso tópico externo das flores da calêndula é indicado para inflamação das mucosas buco-faríngeas e uso externo para feridas e queimaduras (BLUMENTHAL, 1998; PDR, 2000).

Popularmente, o emprego da calêndula é praticamente ilimitado sendo indicada para tratamento de inúmeras enfermidades. Dentre suas inúmeras ações etnoterapêuticas, incluem- se: excitante, emenagoga, anti-espasmódica, antiescorbútica, oftálmica, antisséptica, sudorífica, colagoga, anti-emética, analgésica, antiviral, tonificante da pele (acne), vasodilatadora, emolientes, adstringente, antihelmíntica, vulnerária, bactericida, fungicida, antiabortiva, antialérgica, resolutiva, diurética e diaforética (MOREIRA, 1985, CARIBÉ et al., 1991; MARTINS, 1994); KÖRBES, 1995; FRANCO, 1996; SHAW, 1999; MICHALAK, 1997).

Segundo PDR (2000), a calêndula tem sido usada extensivamente na medicina popular com uso externo para varicose, feridas de doenças vasculares, inflamações na pele, eczema anal, conjuntivites. É um constituinte no tratamento para pele seca, picada de abelhas e ulcerações provocadas pelo frio. Internamente para condições inflamatórias de órgãos internos, úlceras gastrointestinais, constipação, verminose e dismenorréia. Preparações da parte aérea da planta são usadas para circulação, úlceras, espasmos, inchaço das glândulas, icterícia, feridas e eczemas. A erva é usada na Rússia para dor-de-garganta, nas Ilhas Canárias para tosse e cãibras e na China para menstruação irregular. No Brasil, a calêndula é muito utilizada na forma de chá das flores como espasmódica, expectorante e para tratar anemias nervosas. É utilizada para combater inflamações das vísceras, feridas, chagas cancerosas, dor de garganta, alergia e icterícia; as pétalas maceradas em compressas de alcoolato são usadas para feridas abertas (KÖRBES, 1995; MICHALAK, 1997).

\section{TOXICOLOGIAE CONTRA-INDICAÇÕES}

A administração subcrônica do EHA preparado de flores de C. officinalis não produziu efeitos tóxicos sobre a maioria dos parâmetros bioquímicos e hematológicos estudados em ratas Wistar adultas. Entretanto, o aumento dos níveis séricos de uréia e ALT em concentrações elevadas indicaram uma possível sobrecarga renal e hepática (SILVA et al., 2005).

O uso anti-ulcerativo de ácido oleonólico e calendulozida-B tridisida, obtidos de rizomas de $C$. officinalis, não promoveu efeitos sobre o sistema cardiovascular, tônus da musculatura lisa intestinal e diurese renal na excreção de eletrólitos. Estes 
compostos foram avaliados como destituídos de propriedades irritativas e de toxicidade, mesmo em administração crônica (IATSYNO et al., 1978).

O uso anti-ulcerativo de ácido oleonólico e calendulozida-B tridisida, obtidos de rizomas de $C$. officinalis, não promoveu efeitos sobre o sistema cardiovascular, tônus da musculatura lisa intestinal e diurese renal na excreção de eletrólitos. Estes compostos foram avaliados como destituídos de propriedades irritativas e de toxicidade, mesmo em administração crônica (IATSYNO et al., 1978).

Uso não indicado para gestantes devido ao seu potencial efeito emenagogo e abortivo (empírico) (BRINKER, 2001).

Os componentes saponosideos do extrato hidro-alcoólico aumentaram o tempo de sono com hexobarbital em ratos, porcos e gatos (BRINKER, 2001).

\section{REFERÊNCIAS}

AKIHISA, T.; YASUKAWA, K.; OINUMA, H.; KASAHARA, Y.; YAMANOUCHI, S.; TAKIDO, M.; KUMAKI, K.; TAMURA, T. Triterpene alcohols from the flowers of compositae and their anti-inflammatory effects. Phytochemistry, v. 43, n. 6, p. 1255-1260, 1996.

ALONSO J. R. Tratado de fitomedicina: bases clínicas y farmacológicas. Buenos Aires: Isis Ediciones, p. 327-330, 1998.

ALONSO, J. R. Fitomedicina: curso para profissionais da área da saúde. Pharmabooks: São Paulo. 2008. $195 p$.

AMIRGHOFRAN, Z; AZADBAKHT, M; KARIMI, M. H. Evaluation of the immunomodulatory effects of five herbal. Journal of Ethnopharmacology, v. 72, p. 167-172, 2000.

APG III. Angiosperm Phylogeny Group. An update of the Angiosperm Phylogeny Group classification for the orders and families of flowering plants: APGIII. Botanical Journal of the Linnean Society, n. 161, p. 105-121, 2009.

BARBOZA, V. C.; VIEIRA, M. do C.; ZÁRATE, N. A. H.; BOTEGA, S. P.; PADILHA, N. de S.; PAES, C. L. Produção de biomassa de Calendula officinalis L. adubada com fósforo e cama-de-frango. Ciênc. Agrotec., Lavras, v. 33, n. 2, p. 478-483, 2009.

BERTOLINI, A. Z.; VIEIRA, M. C.; HEREDIA, Z.; NÉSTOR, A. Crescimento de Calendula officinalis L. proveniente de três tipos de diásporos. In: JORNADA PAULISTA DE PLANTAS MEDICINAIS: natureza, ciência e comunidade, 5., Botucatu, 2001. Anais... Botucatu: UNESP/UFB, 2001. p. 61.

BERTONI, B. W.; DAMIÃO FILHO, C. F.; MORO, J. R.; FRANÇA, S. C.; PEREIRA, A. M. S. 
Micropropagação de Calendula officinalis L. Rev. Bras. PI. Med., Botucatu, v. 8, n. 2, p. 48-54, 2006.

BLUMENTHAL, M.; BUSSE, W. R. The complete german commission e monographs: therapeutic guide to herbal medicines. Boston:American botanical Council, 1998. 685 p.

BOYOM, F. F.; NGOUANA, V.; ZOLLO, P. H. A.; MENUTC; BESSIERE, J. M.; GUT, J.; CHALCHAT, J. C.; GARRY, R. P. H.; MICHET, A. Chemical Composition of Essential Oil of Calendula officinalis L. (Pot Marigold). Flavour and Fragrance Journal, v. 6, p. 189-192, 1991.

BRINKER, F. Herb contraindications and drug interactions. USA: Ecletic Medical Pub., 2001. 421 p.

BRUNETON, J. Farmacognosia: fitoquímica plantas medicinales. 2. ed. Zaragoza: Acribia, 2001. 1099 p.

CARIBÉ, J.; CAMPOS, J. M. Plantas que ajudam o homem. São Paulo: Cultix/Pensameto, 1991.

CASTRO, L. O.; CHEMALE, V. M. Plantas medicinais condimentares e aromáticas. Guaíba: Agropecuária, 1995.196p.

CENTENO, L. M. M. Plantas medicinales españolas Calendula officinalis L. (Asteraceae). Medicina Naturista, n. 5, p. 257-261, 2004.

CHALCHAT, J. C; GARRY, R. P. H; MICHET, A. Chemical Composition of Essential Oil of Calendula officinalis L. (Pot marigold). Flavour and Fragrance Journal, v. 6, p.189-192, 1991.

CORREAAJUNIOR, C.; MING, L. C.; SCHEFFER, M. C. Cultivo de plantas medicinais, condimentares e aromáticas. 2 ed. Jaboticabal: FUNEP, 1994. 162 p.

CRABAS N; MARONGIU B; PIRAS A; PIVETTA T; PORCEDDAS. Extraction, separation and isolation of volatiles and dyes from Calendula officinalis $\mathrm{L}$. and Aloysia triphylla (L'Her). Britton by supercritical $\mathrm{CO}_{2}$. Journal of Essential Oil Research, v. 15, p. 350-355, 2003.

CROMACK H. T. H.; SMITH J. M. Calendula officinalis: production potential and crop agronomy in southern England. Journal Industrial Crops and Products, v. 7, p. 223-229, 1996.

DELLA LOGGIA et al. The role of triterpenoids in the topical anti-inflamatory activity of Calendula officinalis. Planta Medicine Dec., v. 60, n. 6, p. 516-520, 1994.

Visão Acadêmica, Curitiba, v.13, n.1, Jan. - Mar./2012 - ISSN 1518-5192 
DERKACH, A. Coumarine from influorescens of Calendula officinalis. Khim Prir Soedin, v. 6, p.777, 1986.

DUMENIL, G.; CHEMLI, R.; BALANSAR, G.; GUIRAUD, H.; LALLEMAND, M. Étude des propriétés antibactériennes des fleurs de Souci Calendula officinalis L. et dês teintures mères homéopathiques de C.officinalis L. et C. arvensis L. Annales, 1980.

DURAN V. et al., "Results of the clinical examination of an ointment with marigold (Calendula officinalis) extract in the treatment of venous leg ulcers," Int J Tissue React. v. 27, n. 3, p. 101-6, 2005.

ELIAS, R.; DE MÉO, M.; VIDAL-OLLIVIER, E.; LAGET, M.; BALANSARD, G.; DUMENIL, G. Antimutagenic activity of some saponins isolated from Calendula officinalis L., C. arvensis L. and Hedera helix L. Mutagenesis, v.5, n. 4, p. 327-31, jul. 1990.

EL-SHAZLY, A. M.; HUSSEIN, K. T. Chemical analysis and biological activities of the essential oil of Teucrium leucocladum Boiss. (Lamiaceae). Biochemical Systematics and Ecology, v. 32, p. 665-674, 2004.

EMBRAPA Pantanal. Calêndula. Série Plantas Medicinais, Condimentares e Aromáticas. 2006. Disponível em: <http://www.campinas.snt.embrapa.br/images/plantas/calendula.pdf>.

FRANCO, I. J. Ervas \& Plantas: a medicina dos simples. 10.ed. Erexim: Livraria Vida Ltda, 2005.

FRANCO, L.L. As sensacionais plantas medicinais, campeãs do poder curativo. Curitiba: Santa Mônica, 1996. 241 p.

FRITSCHE, K. et al. Isolation and characterization of a calendic acid producing $(8,11)$ linoleoyl desaturase. FEBS Letters, Ludwigshafen, n. 462, p. 249-253, 1999.

FUENTES, V.; ACOSTA, L.; DURAND, D.; RODRÍGUEZ, C.; MARTINS, G.; RAMOS, R. El cultivo de una espécie medicinal: Calendula officinalis L. Plantas Medicinales, v. 6, p. 28-33, 1986.

GARCÍA, D.; SÁNCHEZ, E.; CRESPO, M.; CARBALLO, C. Estudio farmacognostico de calendula (Calendula officinalis L.). Rev. Cubana Plant Med., v. 1., n. 3, p. 21-25, 1996.

GAZIM, Z. C; FERREIRA, G. A.; REZENDE, C. M.; NAKAMURA, C. V.; DIAS FILHO, B. P.; CORTEZ, D. A. G. Identificação dos constituintes químicos da fração volatile da Calendula officinalis produzida no Paraná. Horticultura Brasileira, v. 25, p. 118-121, 2007. 
GIL, B. Á.; CASTILLO, R. M.; ROQUE, C. G.; FERNÁNDEZ, D. Extracto acuoso de Calendula officinalis. Estudio preliminar de sus propiedades. Rev. Cubana Plant. Med., v. 5, n. 1, p. 30-31, 2000.

GRACZA, L. Oxygen-Containing Terpene Derivatives from Calendula officinalis. Planta Medica, v. 53, p. $227,1987$.

HAMBURGER, M. et al. Preparative purification of the major anti-inflammatory triterpenoid esters from Marigold (Calendula officinalis). Fitoterapia, n. 74, p. 328-338, 2003.

HELALY, F. M; AHMED, A. A; EL-GHAFFAR, M. A. A. Natural rubber base matrix containing Calendula officinalis plant as a source of molluscicidal saponin. Journal of Controlled Release, v. 57, p. 1-7, 1999.

HSIEH, P. C.; MAU, J. L.; HUANG, S. H. Antimicrobial effects of various combinations of plant extracts. Food Microbiology, v. 18, p. 35-43. 2001.

IATSYNO, A. I. et al. Pharmacology of celuloside B, a new triterpene glycoside from the roots Calendula officinalis. Farmakologiia I Toksikologiala, v. 41, n. 5, p. 556-560, 1978.

JIMÉNEZ-MEDINA, E.; GARCIA-LORA, A.; PACO, L.; ALGARRA, I.; COLLADO, A.; GARRIDO, F. A new extract of the plant Calendula officinalis produces a dual in vitro effect: cytotoxic anti-tumor activity and lymphocyte activation. BMC Cancer, v. 6, p. 119-132, 2006.

JIMENEZ-MEDINA, E.; LLAMAS, M.; PACO, L.; ALGARRA, I. GARCIA-LORCA, A. M.; GARRIDOTORRES-PUCHOL PUCHOL, F. A new immunomodulatory acting on Lymphocyte cell proliferation. Genes and Immunity, Supplement 1-p, s70, 2004.

KALVATCHEV, Z.; WALDER, R.; GARZARO, D. Anti-HIV activity of extracts from Calendula officinalis flowers. Biomedical Pharmacotheraphy,v. 51, p. 176-180, 1997.

KÖRBES, C.V. Plantas medicinais, 48. ed. Francisco Beltrão: Associação de Estudos, Orientação e Assistência Rural, 1995. 186p.

LORENZI, H.; MATOS, F. J. A. Plantas medicinais no Brasil: nativas e exóticas cultivadas. 2. ed. São Paulo: Instituto Plantarum, 2008. 544p.

LUZ, L. A. de la; FERRADÁ, C. R.; GOVÍN, E. S. Instructivo Técnico de Calendula officinalis. Rev. Cub. Plant.Med., n.1, p. 23-27, 2001.

MACHADO, I. T. Guia homeopático. 6. ed. São Paulo: Robe Editorial, 2000. 397p. 
MARTINS, C. R. et al. Plantas medicinais. Viçosa: Editora da UFV, 1994. 220p.

MATTOS, J. K. de A. Plantas medicinais: aspectos agronômicos. Brasília, DF: [s.n.], 1996. 51 p.

MICHALAK, E. Apontamentos fitoterápicos da Irmã Eva Michalak. Florianópolis: EPAGRI, 1997. 94p.

MOBOT. Missouri Botanical Garden. W3 tropics. Disponível em: http://mobot.mobot.org /W3T/ search/vast.html. Acesso em: 05 jul. 2010.

MONTANARI JR, I. Aspectos do cultivo comercial de calêndula. Revista Agroecológica Hoje, v. 2, p. 24$25,2000$.

MOREIRA, F. As plantas que curam. São Paulo: Hemus, 1985. 256 p.

MOREIRA, P. A.; MARCHETTI, M. E.; VIEIRA, M. do C.; NOVELINO, J. O.; ROBAINA, A. D.;

GONÇALVES, M. C. Desenvolvimento vegetativo e teor foliar de macronutrientes da calêndula (Calendula officinalis L.) adubada com N e P. Revista Brasileira de Plantas Medicinais, Botucatu, v. 8, n. 1, p. $18-23,2005$.

MULEY, B. P. et al. Phytochemical constituents and pharmacological activities of Calendula officinalis Linn (asteraceae): a review. Tropical Journal Of Pharmaceutical Research, Benin City, v. 5, n. 8, p. 455-465, 2009

MUÑOZ, F. Plantas medicinales y aromáticas. Estudio, cultivo y procesado. Madrid: Editorial MunidPrensa, 1987.365 p.

NARDI, U., CAGLIARDI, L.; PRAMPOLINI, F. Fitocosmesi. La Calendula. Erboristeria Domani, n. 3, p. 62-67, 1991.

OCIOSZYNSKAYA, I. Study of the chemistry of Calendula officinalis in some galenical preparations. Farmatsiya (Moscow), v. 26, n. 1, p. 34-38, 1977.

OSAIDA, C. C.; SILVA JUNIOR, A. A.; OSAIDA, C. Plantas Medicinais: resgate etnobotânico e científico. Canelinha: Harmonia Natural, 2009. 1 CD-ROM.

PAGNANO, L. de O.; BARALDI-ARTONI, S. M.; PACHECO, M. R.; SANTOS, E.; OLIVEIRA, D.; LUI, J. F. Morfometria de fibroblastos e fibrócitos durante o processo cicatricial na pele de coelhos da raça Nova Zelândia Branco tratados com calêndula. Ciência Rural, Santa Maria, v. 38, n. 6, p. 1662-1666, 2008. 
PARENTE, L. M. L.; MATOS, L. G.; CUNHA, L. C.; LEÃO, A. Análise farmacognóstica do pó e avaliação do efeito do extrato etanólico das flores da Calendula officinalis L. cultivadas no Brasil no sistema imunológico. Revista Eletrônica de Farmácia, v. 1, n. 1, p. 9-16, 2004.

PARENTE, L. M. L. et al. Calendula officinalis: características, propriedades químicas e terapêuticas. Arq. Ciênc. Saúde Unipar, v. 6, n. 2, p. 165-169, 2002.

PARKHURSI, R. Saponin-containing spermatocidal compositions. USP, 1975, 3,886, 272.

PDR FOR HERBAL MEDICINE. 2nd ed. New Jersey: Montvale, p. 497-99, 2000.

PEREZ, M. P.; NAVAS-CORTES, J. A.; PASCUALVILLALOBOS, M. J.; CASTILLO, P. Nematicidal activity of essential oils and organic amendments from Asteraceae against root-knot nematodes. Plant Pathology, v. 52, p. 395-401, 2003.

PIETTAP; BRUNOA; MAURI P; RAVAA. Separation of flavonol-2-O-glycosides from Calendula officinalis and Sambucus nigra by high-performance liquid and micellar electrokinetic capillary chromatography. Journal of Chromatography, v. 93, p. 165-170, 1992.

PIETTA P; FACINO R. M.; CARINI M.; MAURI P. Thermospray liquid chromatographymass spectrometry of flavonol glycosides from medicinal plants. Journal of Chromatography, v. 661, p.121-126, 1994.

PLANTAMED. Calêndula. Disponível em: http://www.plantamed.com.br/.

RADULESCU, V; DONEANU, C; LOLOIU, T. G. C. Investigation of chemical composition of Calendula officinalis. Revue Roumaine de Chimie, v. 45, p. 271-275, 2000.

RAMOS, A.; EDREIRA, A.; VIZOSO, A.; BETANCOURT, J.; LÓPEZ, M.; DÉCALO, M. Genotoxicity of an extract of Calendula officinalis L. Journal of Ethnopharmacology, v.61, p. 49-55, 1998.

REZNICEK G; ZITTERL-EGLSEER K. Quantitative determination of the faradiol esters in marigold flowers and extracts. Scientia Pharmaceutica, v. 71, p. 121-128, 2003.

ROIG, J. T. Plantas medicinales, aromáticas o venenosas de Cuba. La Habana: Editorial Ciencia y Técnica, 1974.939p.

SERGEEVA, N. V. Qualitative and quantitative study of carotenóide in some galenical preparations. Farmatsiya (Moscow), v. 26, n. 1, p. 34-8, 1977.

SHAW, N. Fitoterapia: guia prático. São Paulo: Avatar, 1999. 58p.

Visão Acadêmica, Curitiba, v.13, n.1, Jan. - Mar./2012 - ISSN 1518-5192 
SCHEFFER, J. J. C. De goudsbloem (Calendula officinalis, L.,) als geneeskruid in verleden en heden. Pharmaceutisch weekblad, v. 114, p. 1149-1157,1979.

SCHULZ V; HANSEL R; TYLER V. E. Fitoterapia racional: um guia de fitoterapia para as ciências da saúde. São Paulo: Ed. Manole, 2002.316 p.

SILVAJUNIOR, A. A. Essentia herba. v. 2. Florianópolis: EPAGRI, 2006. 633p.

SILVA, E. J. R. et al . Avaliação do tratamento subcrônico com o extrato hidroalcoólico de Calendula officinalis L. sobre os parâmetros bioquímicos e hematológicos em ratas Wistar. Rev. bras. farmacogn., João Pessoa, v. 15, n. 2, 2005.

SIMÕES, C.M.O. et al. Farmacognosia: da planta ao medicamento. 5.ed. rev. ampl. Porto Alegre: UFRGS, 2003. $1102 \mathrm{p}$.

SINGH, A. K. Response of pot marigold (Calendula offlicinalis) to plant growth regulators. Indian Journal of Agricultural Sciences, v. 74, p. 130-132, 2004.

STEVENSON R. Some constituents of Calendula officinalis. Helvetica Chimica Acta,v. 31, p. 1815, 1961.

SWISTEK I. Phenolic acids in the inflorescens of Arnica montana and Calendula officinalis. Herba Pol, v. 24, n. 4, p. 167-92, 1978.

TOMAS, M. Studies on triterpenoid saponins in indigenous medicinal plants. Stud Cercet Biochem, v. 21, n. 1, p. 89-94, 1978

VALDÉZ, H. L., GARCÍA, R. P. Calendula officinalis. Rev Cubana Farm, v. 33, p. 188-194, 1999.

VARLJEN, J.; LIPPTAK, A.; WAGNERT, H. Structural analysis a rhamnoarabiainogalactatan and arabinogalactans with immuno-stimulating activity from Calendula officinalis. Phytochemistry Riijeka, v. 28, n. 9, p. 2379-2383, 1989.

VAZ, A. P. A.; JORGE, M. H. A. Calêndula. Corumbá: EMBRAPA, 2006. 2p. (Série Plantas Medicinais, Condimentares e Aromáticas).

VIEIRA, M. C.; HEREDIA ZÁRATE, N. A.; RAMOS, M. B. M. Crescimento e produção de capítulos de Calendula officinalis L., em função de cama-de-aviário semi-decomposta e de fósforo. Rev. Bras. de PI. Med., Botucatu, v. 1, n. 2, p. 45-51, 1999. 
VIEIRA, M. C. et al. Crescimento e produção de biomassa de calêndula (Calendula officinalis L.) proveniente de dois tipos de diásporos e duas colorações de capítulos florais. Rev. Bras. PI. Med., Botucatu, v. 8, n. 4. p. 193-197, 2006.

WAGNER H. Immunoestimulating polysacharides of higher plants. Arzeneim iltely, forschung, v. 34, n. 6, p. 659-61, 1984 .

WHO-World Health Organization. Monographs on selected medicinal plants, 2. Geneva, 2002. 356p.

WILKOMIRSKI, B. Pentacyclic triterpene triols from Calendula officinalis flowers. Phytochemistry, v. 24, p. 3066-3067, 1985.

YOSHIKAWA, M. et al. Hypoglycemic, Gastric Emptying Inhibitory, and Gastroprotective Principles and New Oleanane-Type Triterpene Oligoglycosides, Calendasaponins A, B, C, and D, from Egyptian Calendula officinalis. Chem. Pharm., v. 49, n. 7, p. 863-870, 2001. 